\title{
Acute ascending aortic dissection: Support for limited distal repair
}

\author{
Joseph S. Coselli, MD
}

See related article on pages 2117-22.

Despite the significant evolution of the surgical treatment of acute type A aortic dissection, repair remains a challenge and is associated with significant morbidity and mortality. Controversy remains regarding the proximal and distal extent of aortic resection in patients undergoing such repairs. Although replacement of the entire transverse aortic arch may prevent the need for additional surgical intervention later, this approach incurs increased risks of stroke and mortality; if repair is extended beyond the left subclavian artery, there is the additional risk of paraplegia. On the proximal end of repair, most surgeons accept the risks associated with full root replacement in the treatment of patients with aneurysm of the root, a connective tissue disorder, or anatomy compromised by destruction caused by aortic dissection.

In this issue of the Journal of Thoracic and Cardiovascular Surgery, Wang and colleagues ${ }^{1}$ from the division of cardiovascular surgery at Mayo Clinic in Rochester, Minnesota, provide insight into their experience with 269 patients operated on for acute ascending aortic dissection. Wang and colleagues ${ }^{1}$ reviewed their 42 -year experience in the surgical management of this disease and report on both long-term survival and freedom from subsequent aortic root or valve operation. Wang and colleagues ${ }^{1}$ included only patients who underwent median sternotomy and excluded those with previous cardiac operations, concomitant total aortic arch replacement, iatrogenic aortic dissection, and primary repair of the ascending aorta. Operative mortalities were remarkably similar for those who received a composite valve graft $(25 \%)$, aortic root repair $(42 \%)$, or isolated supracoronary ascending aortic replacement $(34 \%)$. In addition, there was little change in mortality during the decades reviewed. Survivals at 10 and 20 years were $65.5 \% \pm 3.6 \%$ and $28.7 \% \pm 4.3 \%$, respectively. Interestingly, survival did not differ by procedure type. Notably, only 20 patients required reoperation during the follow-up period, and there were no differences

\footnotetext{
From the Division of Cardiothoracic Surgery, Michael E. DeBakey Department of Surgery, Baylor College of Medicine; and the Department of Cardiovascular Surgery, Texas Heart Institute, Houston, Tex.

Disclosures: Author has nothing to disclose with regard to commercial support.

Received for publication Sept 19, 2014; accepted for publication Sept 20, 2014.

Address for reprints: Joseph S. Coselli, MD, One Baylor Pl, BCM 390, Houston,

TX 77030 (E-mail: jcoselli@bcm.edu).

J Thorac Cardiovasc Surg 2014;148:2123-4

$0022-5223 / \$ 36.00$

Copyright (C) 2014 by The American Association for Thoracic Surgery

http://dx.doi.org/10.1016/j.jtcvs.2014.09.069
}

among the 3 types of repairs with respect to the freedom from reoperation on the aortic valve or aortic root. Interestingly, Wang and colleagues ${ }^{1}$ identified no specific factors predictive of reoperation. Despite the distal end of repair being limited to a hemiarch approach at most, reoperation on the distal aorta or arch was notably uncommon and occurred in only 6 patients $(2.7 \%)$.

There continues to be debate in the literature as to whether to extend proximally or distally ascending aortic repair in patients with acute type A aortic dissection. At the proximal end of repair, Moon and associates ${ }^{2}$ concluded that an aggressive surgical approach, including full root replacement, was not associated with increased operative risk and should be considered in patients with acute type A aortic dissection. They also stressed taking an individualized approach to repair, however, suggesting that the aortic valve be preserved when anatomically appropriate and feasible. At the distal end of repair, Chang and coworkers ${ }^{3}$ reviewed data from 21 patients with acute type A aortic dissection who underwent comprehensive arch repair by a hybrid approach (which involved endovascular repair of the entire transverse aortic arch). Their results suggested that this more aggressive extension of traditional reconstruction allowed for a respectable in-hospital mortality of $4.8 \%$ and could potentially reduce late adverse events arising from enlargement of the false lumen in the arch and descending thoracic aorta.

The important point of the current report by Wang and colleagues $^{1}$ is that a conservative approach can address the primary objectives of operative intervention for acute type I aortic dissection-preventing rupture of the aorta, correcting malperfusion, establishing blood flow into the true lumen, and retaining a competent aortic valve-albeit with a very individualized approach that allows for surgical bias (surgeon judgment). When connective tissue disorder or anatomic destruction of the aortic valve and aortic root indicate root replacement, this can be done effectively. As an alternative, valve preservation through aortic valvesparing techniques, resuspension, or isolated replacement of the ascending aorta produced similar results. In either case, good outcomes for both early and long-term survival can be readily achieved. Although Wang and colleagues ${ }^{1}$ point out surgical bias as a limitation of their study, one interpretation may be that this actually is the cornerstone of their study and that it represents the underpinning of surgical judgment.

When good surgical judgment is applied to the aortic valve and root, Wang and colleagues ${ }^{1}$ show that the freedoms from reoperation on the aortic valve or root are 
very respectable at 10 years $(91.5 \% \pm 2.3 \%)$ and 20 years $(79.3 \% \pm 6.1 \%)$. Similarly, the use of a conservative approach to the distal end of the repair-that is, an approach that did not include extended repair with transverse aortic arch replacement-resulted in only 6 patients $(2.7 \%)$ who required reoperation on the distal aorta or aortic arch during their follow-up and allowed for an outstanding freedom from reoperation on the distal aorta of $97.2 \% \pm 1.3 \%$ at both 10 and 20 years.

\section{References}

1. Wang Z, Greason KL, Pochettino A, Schaff HV, Suri RM, Stulak JM, et al. Long-term outcomes of survival and freedom from reoperation on the aortic root or valve after operation for acute ascending aorta dissection. J Thorac Cardiovasc Surg. 2014;148:2117-22.

2. Moon MR, Sundt TM III, Pasque MK, Barner HB, Huddleston CB, Damiano RJ Jr, et al. Does the extent of proximal or distal resection influence outcome for type A dissections? Ann Thorac Surg. 2001;71:1244-9; discussion $1249-50$.

3. Chang Q, Tian C, Wei Y, Qian X, Sun X, Yu C. Hybrid total arch repair without deep hypothermic circulatory arrest for acute type A aortic dissection (R1). J Thorac Cardiovasc Surg. 2013;146:1393-8. 